\title{
Metabolic Syndrome Prevalence in Students Attending West Virginia University
}

\author{
Melissa D. Olfert *(D), Amanda Dent and Rachel A. Wattick \\ Division of Animal and Nutritional Sciences, Davis College of Agriculture, Natural Resources and Design, \\ West Virginia University, 1194 Evansdale Dr., Office G27, Morgantown, WV 26506, USA; \\ amandamariedent@gmail.com (A.D.); rawattick@mix.wvu.edu (R.A.W.) \\ * Correspondence: Melissa.olfert@mail.wvu.edu; Tel.: +1-304-293-2232
}

Received: 2 October 2018; Accepted: 22 November 2018; Published: 27 November 2018

check for updates

\begin{abstract}
Metabolic Syndrome (MetS) contributes to the development of cardiovascular disease (CVD) and type II diabetes mellitus (T2DM). Few studies have investigated the MetS risk of young adults (18-24 years old). This study aims to determine the prevalence of MetS in Appalachian and non-Appalachian students attending West Virginia University. The prevalence of MetS in this population was $15 \%$. There was no difference in MetS prevalence between male students and female students $(18.8 \%$ males and $11.1 \%$ females, $p$-value $=0.30)$, or between Appalachian students and non-Appalachian students $(17.7 \%$ Appalachian and 10.0\% non-Appalachian, $p$-value $=0.33)$. Identification of MetS early in life is needed in order to reduce the onset of chronic disease. Therefore, implementing a screening process to identify at-risk young adults will help tailor more effective behavioral interventions.
\end{abstract}

Keywords: metabolic syndrome; Appalachia; college students; metabolic syndrome

\section{Introduction}

Metabolic Syndrome (MetS) contributes to the development of coronary heart disease (CHD) [1-3], cardiovascular disease (CVD) [3], and type II diabetes mellitus (T2DM) [1-3]. MetS consists of five, interrelated risk factors $[4,5]$. Individuals presenting three or more of the following risk factors are diagnosed with MetS: Fasting blood glucose (FBG) $\geq 100 \mathrm{mg} / \mathrm{dL}$, waist circumference (WC) $>102 \mathrm{~cm}$ for men and $>88 \mathrm{~cm}$ for women, triglycerides (TG) $\geq 150 \mathrm{mg} / \mathrm{dL}$, high density lipoprotein cholesterol (HDL) $<40 \mathrm{mg} / \mathrm{dL}$ for men and $<50 \mathrm{mg} / \mathrm{dL}$ for women, and blood pressure (BP) $\geq 130 / 85 \mathrm{mmHg}$ [6].

Few studies have investigated the MetS risk of young adults [1,7]. However, CHD is the second leading cause of death in this age group [1], suggesting the need to detect for early warning signs of this disease. Thus, screening for MetS in this population can be beneficial in identifying those at higher risk from CHD development.

The prevalence of obesity has reached epidemic proportions within the Appalachian region [8,9], which extends from Northeastern Mississippi to Southern New York [10], with its epicenter lying entirely within the state of West Virginia (WV) [11]. The Appalachian region is characterized by unhealthy eating behaviors and inactivity, which leads to the increased incidence of chronic disease among this population [10]. Ely et al. recently reported the increased risk of chronic disease, related to excessive weight gain and poor health behaviors, is not realistically perceived by Appalachian residents [12]. Inadequate transportation [8], poverty [13,14], lack of access to medical care $[8,13]$ and lack of insurance are additional factors directly impacting the health disparities of individuals in this region [13]. In 2009, Appalachians were $40 \%$ more likely to have diabetes than non-Appalachians [8]. In 2011, the prevalence of diagnosed diabetes was $9.8 \%$ within the Appalachian region and $7.8 \%$ in the rest of the nation [15]. 
In Ohio and WV, $25.6 \%$ of normal-weight adults display two or more of the following cardio-metabolic abnormalities: High blood pressure, elevated TG, decreased HDL, elevated FBG, and insulin resistance (IR) [9]. An estimated 50\% of adults and adolescents residing in WV are obese by Body Mass Index (BMI) classification: Normal weight $\left(18.5-24.9 \mathrm{~kg} / \mathrm{m}^{2}\right)$, overweight $\left(25.0-29.9 \mathrm{~kg} / \mathrm{m}^{2}\right)$, and obese $\left(\geq 30 \mathrm{~kg} / \mathrm{m}^{2}\right)$ [8]. WV has reported the highest age-adjusted incidence of diabetes as well as the highest diabetes-related deaths in the nation [8].

As many as $30 \%$ to $35 \%$ of college students are reported to be overweight or obese $[7,16,17]$ and obesity rates have increased most rapidly among individuals 18-29 years old with some college education [7,16-18]. First year college students gain weight up to 11 times faster than adults [1]. This increase in weight increases the likelihood of developing MetS risk criteria [1,7]. Increased weight and obesity, particularly abdominal obesity, is directly related to the development of MetS and cardiovascular risk [5,19]. Screening for abnormal lipid values is recommended starting at 20 years old [1]. Therefore, colleges and universities serve as important settings for the surveillance, prevention, and intervention of hyperlipidemia, MetS, and CHD [20]. Targeting young adults that choose to attend post-secondary institutions could aid in the prevention of CVD, CHD, and T2DM since many young people develop a clearer sense of self and establish life-long behavior patterns during college [21].

The few studies of MetS prevalence in college students found that 27\% [17], 28\% [1], and 30\% [16] of students in the Northeast [1] and Midwest $[16,17]$ regions exhibit at least one component of MetS. In the same studies, 5.7\% [16], 7.4\% [1], and 14.3\% [17] of college students had two components of MetS. In the Southern US, $43 \%$ of students presented with at least one component of MetS [7]. When the sample was limited to students who were overweight or obese, the rate of at least one component of MetS rose to $82 \%$ [7]. Fernandes et al. found that 3.7\% of college students presented with three or more MetS risk components [1]. The latest study, conducted by Morrell et al., reported $77.2 \%$ of males and 53.8\% of females exhibited at least one component of MetS [22]. MetS was present in 9.9\% of males and 3.0\% females [22]. Not only do overweight [1,17,22] and obese [1,22] students present with MetS [1] and more MetS risk factors [17,22] than normal weight students, but obese students exhibit significantly more MetS criteria than overweight students [22]. Overall, male students were more likely to exhibit MetS risk criteria than female students [16] and the most prevalent MetS risk component was low HDL $[16,17,22]$, then FBG, and TG in decreasing order $[16,17]$.

Due to the overall poorer health and higher risk factors in the Appalachian region discussed previously, young adults in these regions are an important, yet overlooked, demographic to study their MetS risk. This study aims to determine the prevalence of MetS in Appalachian and non-Appalachian students attending West Virginia University.

\section{Method}

The measures for this cross-sectional study were collected in January and February 2011. Subjects were recruited from West Virginia University. The Institutional Review Board (IRB) at West Virginia University approved the study protocol in advance of commencement.

\subsection{Subjects}

Subjects $(n=93)$ were recruited via posted advertisements, in-class announcements, and recruitment E-mails sent by instructors and campus administrators. Students were eligible if they were 18-24 years old; had a BMI $>18.5 \mathrm{~kg} / \mathrm{m}^{2}$; were a first, second, or third year undergraduate; had regular access to the Internet; were free from life-threatening illnesses or other health conditions; were not pregnant; had no diet- and/or activity-related medical restrictions that prevented accurate physical assessments; they were not currently enrolled in a nutrition course; and they were not majoring in nutrition, exercise science, or health-promotion. 


\subsection{Measures}

Demographics (e.g., ethnicity), health-related practices (e.g., cigarette and medication use), and Appalachian identity (from self-reported home address) were collected via questionnaire. All clinical, anthropometric, and biochemical measurements were performed by trained staff. Measurements were collected in the fasted state $(>8 \mathrm{~h})$ after participants had changed into light clothing and voided. All female participants were screened for pregnancy.

Systolic and diastolic pressures were measured in triplicate (with 2 min rest intervals) in the left arm midpoint between the shoulder and elbow via an automated cuff (HEM-907XL, Omron; Lake Forest, IL, USA) after subjects were rested in a seated position for five minutes. Height was measured by a wall-mounted, digital stadiometer (Heightronic 235, Quick Medical; Issaquah, WA, USA) with subjects looking straight ahead and maintaining four points of contact (heels, buttocks, shoulder blades, and back of the head) with the wall. Weight was measured by a digital scale (300A, Tanita; Arlington Heights, IL, USA) which also calculated body mass index (BMI) from height input. Waist circumference (WC) was measured in duplicate at the top of the iliac crest to the nearest $0.1 \mathrm{~cm}$ using a non-stretchable tape measure with tensometer (Gulick, Creative Health Products; Plymouth, MI, USA). Neck circumference (NC) was measured in duplicate at the point below the larynx to the nearest $0.1 \mathrm{~cm}$ with the tape measure used for waist circumference.

Biochemical measures were obtained via finger-stick using a desktop LDX Cholestech Analyzer (LDX, Cholestech; San Diego, CA, USA) following manufacturer's instructions. Analyses for high-density lipoprotein cholesterol (HDL), triglycerides (TG), fasting blood glucose (FBG), C-Reactive Protein (CRP), and low-density lipoprotein cholesterol (LDL) were conducted via direct enzymatic methods by the analyzer. The Cholestech LDX analyzer has been validated for precision and accuracy against traditional laboratory techniques and offers logistical convenience for large-scale health assessments [23]. Hemoglobin A1C (HbA1C) was measured using DCA Vantage. Hemoglobin $(\mathrm{Hgb})$ and hematocrit (Hct) weer measured using HemoPoint A2 (Boerne, TX, USA).

\subsection{Statistical Analysis}

BMI was categorized as normal weight $\left(18.5-24.9 \mathrm{~kg} / \mathrm{m}^{2}\right)$, overweight $\left(25.0-29.9 \mathrm{~kg} / \mathrm{m}^{2}\right)$, and obese $\left(\geq 30.0 \mathrm{~kg} / \mathrm{m}^{2}\right)$. MetS and its five individual components were defined by the National Cholesterol Education Program Adult Treatment Panel III: Fasting blood glucose (FBG) $\geq 100 \mathrm{mg} / \mathrm{dL}$, waist circumference (WC) $>102 \mathrm{~cm}$ for men and $>88 \mathrm{~cm}$ for women, triglycerides (TG) $\geq 150 \mathrm{mg} / \mathrm{dL}$, high density lipoprotein cholesterol (HDL) $<40 \mathrm{mg} / \mathrm{dL}$ for men and $<50 \mathrm{mg} / \mathrm{dL}$ for women, and blood pressure (BP) $\geq 130 / 85 \mathrm{mmHg}$ [6]. The presence of $\geq 3 / 5$ components was categorized as MetS.

Student $t$-tests were performed to identify differences in anthropometric and biochemical measures between males and females and Appalachians and non-Appalachians. Chi-square tests were used to identify associations between prevalence rates of individual components and MetS, and the following subject characteristics: Male, female, Appalachian, and non-Appalachian. The Mantel-Haenszel test was used to assess the ordinal trend between males and females as well as Appalachians and non-Appalachians. Statistical significance was defined as a $p$-value $<0.05$. Statistical analyses were performed using SAS 9.3 statistical software (SAS Institute Inc., Cary, NC, USA).

\section{Results}

Subjects were $51.6 \%$ male and $48.4 \%$ female; primarily White $(82.8 \%)$ followed by Black $(10.7 \%)$, Latino (3.2\%) and Asian (2.2\%). Roughly, two thirds of the subjects identified themselves as Appalachian (67.7\%) and one third as non-Appalachian (32.3\%). The majority (41.9\%) of subjects were first year, $30.1 \%$ were second year, and $25.8 \%$ third year undergraduate students. Table 1 provides more descriptive characteristics. 
Table 1. Sample descriptive characteristics.

\begin{tabular}{lcc}
\hline & Total $(\boldsymbol{n}=\mathbf{9 3})$ & Percentage $\mathbf{( \% )}$ \\
\hline Sex & & \\
Female & 45 & 48.4 \\
Male & 48 & 51.6 \\
\hline Ethnicity & & \\
Caucasian & 77 & 82.8 \\
African American & 10 & 10.7 \\
Hispanic/Latino & 3 & 3.2 \\
Asian & 2 & 2.2 \\
Not reported & 1 & 1.1 \\
\hline Permanent address & & \\
Appalachian & 63 & 67.7 \\
Non-Appalachian & 30 & 32.3 \\
\hline School year & & \\
First & 39 & 41.9 \\
Second & 28 & 30.1 \\
Third & 24 & 25.8 \\
Not reported & 2 & 2.2 \\
\hline
\end{tabular}

Table 2 shows that average subjects had normal BMIs with no significant differences between male and female) subjects ( $p$-value $=0.29$ ). Waist circumference did not differ between male and female subjects $(p$-value $=0.58)($ Table 2$)$. Males weighed significantly more than females $(p$-value $<0.01)$ (Table 2). Female students presented with significantly higher HDL levels compared to males $(p<0.01)$ (Table 3). Male students had higher systolic BP $(p$-value $<0.001)$, but not diastolic BP than females $(p$-value $=0.60)($ Table 3$)$. No sex differences were observed for TG and FBG (Table 3$)$.

Table 2. Baseline anthropometric measures by sex.

\begin{tabular}{cccccccc}
\hline & \multicolumn{2}{c}{ All $(\boldsymbol{n}=\mathbf{9 3})$} & \multicolumn{2}{c}{ Female $(\boldsymbol{n}=\mathbf{4 5})$} & \multicolumn{2}{c}{ Male $(\boldsymbol{n}=\mathbf{4 8 )}$} & Sex Differences \\
\hline Measures & Mean & SD & Mean & SD & Mean & SD & $\boldsymbol{p}$-Value \\
\hline Height $(\mathrm{cm})$ & 171.87 & 8.94 & 165.01 & 5.20 & 178.30 & 6.63 & $<0.0001^{*}$ \\
Weight $(\mathrm{kg})$ & 73.04 & 15.58 & 68.74 & 16.53 & 77.08 & 13.61 & $0.0092^{*}$ \\
BMI $\left(\mathrm{kg} / \mathrm{m}^{2}\right)$ & 24.70 & 4.81 & 25.25 & 5.82 & 24.19 & 3.61 & 0.2930 \\
BF $(\%)$ & 22.84 & 10.64 & 30.22 & 8.89 & 15.91 & 6.79 & $<0.0001$ * \\
WC $(\mathrm{cm})$ & 84.13 & 15.73 & 85.07 & 19.77 & 83.25 & 10.80 & 0.5796 \\
NC $(\mathrm{cm})$ & 35.68 & 3.70 & 33.04 & 3.12 & 38.17 & 2.17 & $<0.0001$ *
\end{tabular}

SD: Standard Deviation; BMI: Body Mass Index; BF: Body Fat; WC: Waist Circumference; NC: Neck Circumference; * indicates significance.

Table 3. Baseline biochemical measures by sex.

\begin{tabular}{cccccccc}
\hline & \multicolumn{2}{c}{ All $(\boldsymbol{n}=\mathbf{9 3})$} & \multicolumn{2}{c}{ Female $(\boldsymbol{n}=\mathbf{4 5})$} & \multicolumn{2}{c}{ Male $(\boldsymbol{n}=\mathbf{4 8})$} & Sex Differences \\
\hline Characteristic & Mean & SD & Mean & SD & Mean & SD & $\boldsymbol{p}$-Value \\
\hline SBP $(\mathrm{mmHg})$ & 117.74 & 13.23 & 111.27 & 9.68 & 123.80 & 13.30 & $<0.0001^{*}$ \\
DBP $(\mathrm{mmHg})$ & 69.41 & 8.97 & 69.91 & 9.21 & 68.94 & 8.82 & 0.6038 \\
LDL-C (mg/dL) & 97.73 & 29.23 & 100.18 & 27.00 & 95.14 & 31.60 & 0.4618 \\
HDL-C (mg/dL) & 53.06 & 18.79 & 58.84 & 18.31 & 47.65 & 17.76 & $0.0035^{*}$ \\
TC $(\mathrm{mg} / \mathrm{dL})$ & 165.72 & 36.54 & 176.82 & 38.06 & 155.30 & 32.08 & $0.004^{*}$ \\
TG $(\mathrm{mg} / \mathrm{dL})$ & 99.51 & 57.69 & 107.38 & 61.86 & 92.13 & 53.06 & 0.2043 \\
FBG $(\mathrm{mg} / \mathrm{dL})$ & 98.84 & 13.87 & 97.38 & 15.97 & 100.21 & 11.57 & 0.3280 \\
HBA1c $(\%)$ & 5.28 & 0.40 & 5.31 & 0.50 & 5.25 & 0.29 & 0.4869 \\
\hline
\end{tabular}

SD: Standard Deviation; SBP: Systolic Blood Pressure; DBP: Diastolic Blood Pressure; LDL-C: Low Density Lipoprotein Cholesterol; HDL-C: High Density Lipoprotein Cholesterol; TC: Total Cholesterol; TG: Triglycerides; FBG: Fasting Blood Glucose; HBA1c: Hemoglobin A1C; * Indicates Significance. 
Appalachian and non-Appalachian student comparisons revealed no significant differences in anthropometric measures (height, weight, BMI, and WC) or biochemical measures (HDL, TG and FBG) (Table 4). Appalachian students presented with elevated FBG (37.1\%), low HDL (35.5\%), at-risk WC $(21.0 \%)$, elevated TG $(21.0 \%)$, and elevated BP (19.4\%). Non-Appalachian students presented with elevated FBG $(36.7 \%)$ low HDL $(36.7 \%)$, elevated BP (23.3\%), at-risk WC $(16.7 \%)$ and elevated TG (13.3\%) (Table 5). The prevalence of individual MetS components was not significantly different between Appalachian and non-Appalachian students.

Table 4. Biochemical and anthropometric measures by region.

\begin{tabular}{|c|c|c|c|c|c|c|c|}
\hline \multirow[b]{2}{*}{ Characteristic } & \multicolumn{2}{|c|}{$\begin{array}{c}\text { All } \\
(n=93)\end{array}$} & \multicolumn{2}{|c|}{$\begin{array}{l}\text { Appalachian } \\
\quad(n=62)\end{array}$} & \multicolumn{2}{|c|}{$\begin{array}{l}\text { Non-Appalachian } \\
\quad(n=30)\end{array}$} & \multirow{2}{*}{$\begin{array}{c}\begin{array}{c}\text { Regional } \\
\text { Differences }\end{array} \\
p \text {-value }\end{array}$} \\
\hline & Mean & SD & Mean & SD & Mean & SD & \\
\hline Height (cm) & 171.87 & 8.94 & 170.94 & 9.00 & 174.22 & 8.33 & 0.097 \\
\hline Weight (kg) & 73.04 & 15.58 & 73.19 & 16.78 & 73.05 & 13.3 & 0.968 \\
\hline BMI $\left(\mathrm{kg} / \mathrm{m}^{2}\right)$ & 24.70 & 4.81 & 25.04 & 5.40 & 23.99 & 3.34 & 0.332 \\
\hline $\mathrm{BF}(\%)$ & 22.84 & 10.64 & 23.37 & 11.27 & 21.45 & 9.30 & 0.420 \\
\hline $\mathrm{WC}(\mathrm{cm})$ & 84.13 & 15.37 & 83.28 & 13.56 & 82.67 & 9.38 & 0.825 \\
\hline $\mathrm{NC}(\mathrm{cm})$ & 35.68 & 3.70 & 35.51 & 3.79 & 36.12 & 3.58 & 0.466 \\
\hline SBP (mmHg) & 117.74 & 13.23 & 117.63 & 12.92 & 118.07 & 14.27 & 0.833 \\
\hline DBP (mmHg) & 69.41 & 8.97 & 70.18 & 8.60 & 67.93 & 9.80 & 0.265 \\
\hline LDL-C (mg/dL & 97.93 & 29.23 & 101.21 & 32.39 & 87.81 & 16.50 & 0.076 \\
\hline HDL-C (mg/dL) & 53.06 & 18.79 & 53.34 & 19.55 & 52.50 & 17.75 & 0.843 \\
\hline $\mathrm{TC}(\mathrm{mg} / \mathrm{dL})$ & 165.72 & 36.64 & 171.39 & 38.58 & 152.77 & 28.43 & 0.021 * \\
\hline $\mathrm{TG}(\mathrm{mg} / \mathrm{dL})$ & 99.51 & 57.69 & 104.95 & 60.17 & 87.00 & 51.64 & 0.164 \\
\hline $\mathrm{FBG}(\mathrm{mg} / \mathrm{dL})$ & 98.84 & 13.87 & 99.02 & 15.43 & 98.30 & 10.40 & 0.819 \\
\hline HBA1c $(\%)$ & 5.28 & 0.40 & 5.32 & 0.44 & 5.18 & 0.29 & 0.115 \\
\hline
\end{tabular}

SD: Standard Deviation; BMI: Body Mass Index; BF: Body Fat; WC: Waist Circumference; NC: Neck Circumference; SBP: Systolic Blood Pressure; DBP: Diastolic Blood Pressure; LDL-C: Low Density Lipoprotein Cholesterol; HDL-C: High Density Lipoprotein Cholesterol; TC: Total Cholesterol; TG: Triglycerides; FBG: Fasting Blood Glucose; HBA1c: Hemoglobin A1C; * indicates significance.

Table 5. Rates of individual metabolic syndrome components.

\begin{tabular}{cccccccc}
\hline \multirow{2}{*}{ MetS Component } & \multicolumn{7}{c}{ Number (\%) with MetS Component (Total $\boldsymbol{n}$ /Percentage \%) } \\
\cline { 2 - 7 } & Overall & Males & Females & $\boldsymbol{p}$-Value & App & Non-App & $p$-Value ${ }^{\mathbf{1}}$ \\
\hline Elevated WC & $18(19.4 \%)$ & $4(8.3 \%)$ & $14(31.1 \%)$ & $0.0055^{*}$ & $13(21.0 \%)$ & $5(16.7 \%)$ & 0.6259 \\
Elevated BP & $19(20.4 \%)$ & $15(31.3 \%)$ & $4(8.9 \%)$ & $0.0075 *$ & $12(19.4 \%)$ & $7(23.3 \%)$ & 0.6586 \\
Elevated TGs & $17(18.3 \%)$ & $8(16.7 \%)$ & $9(20.0 \%)$ & 0.6777 & $13(21.0 \%)$ & $4(13.3 \%)$ & 0.3765 \\
Elevated FBG & $35(37.6 \%)$ & $23(47.9 \%)$ & $12(26.7 \%)$ & $0.0345 *$ & $23(37.1 \%)$ & $11(36.7 \%)$ & 0.968 \\
Low HDL-C & $33(35.5 \%)$ & $19(39.6 \%)$ & $14(31.1 \%)$ & 0.3935 & $22(35.5 \%)$ & $11(36.7 \%)$ & 0.9117 \\
\hline
\end{tabular}

App: Appalachian; WC: Waist Circumference; BP: Blood Pressure; TGs: Triglycerides; FBG: Fasting Blood Glucose; HDL-C: High Density Lipoprotein Cholesterol; ${ }^{1}$ Chi-Square test; ${ }^{*}$ indicates significance.

The most prevalent MetS component in the total sample was elevated FBG (37.6\%), followed by low HDL (35.5\%), elevated BP (20.4\%), at-risk WC (19.4\%) and elevated TG (18.3\%) (Table 5). Male students presented with elevated FBG (47.9\%), followed by low HDL (39.6\%), elevated BP (31.3\%), elevated TG $(16.7 \%)$, and at-risk WC (8.3\%), whereas, female students presented with low HDL (31.1\%) and at-risk WC (31.1\%), followed by elevated FBG $(26.7 \%)$, elevated TG $(20.0 \%)$, and elevated BP $(8.9 \%)$ (Table 5). Overall, significantly more female students exhibited at-risk WC than males $(p<0.01)$, whereas, significantly more male students displayed elevated BP $(p<0.01)$ and FBG $(p<0.05)$ (Table 5$)$.

Twenty-eight percent of students presented with zero components of MetS; $33.1 \%$ with one component; and $23.7 \%$ with two components (Table 6). The prevalence of MetS in this population was $15 \%$. Specifically, $10.8 \%$ presented with three components, $3.2 \%$ with four components, and $1.1 \%$ with all five components of MetS (Table 6). There was no significant difference between male and female students in MetS prevalence ( $p$-value $=0.30$ ) or between Appalachian students and non-Appalachian 
students $(p$-value $=0.33)$ (Table 6). There were no significant associations between the number of MetS components by sex $(p=0.28)$ or by Appalachian identity $(p=0.78)$ (Table 6).

Table 6. Frequency of metabolic syndrome and number of metabolic syndrome components.

\begin{tabular}{|c|c|c|c|c|c|c|c|c|c|c|}
\hline \multirow{2}{*}{$\begin{array}{l}\text { Demographic } \\
\text { Variable }\end{array}$} & \multirow{2}{*}{$n$} & \multirow{2}{*}{$\begin{array}{l}\text { Total } n(\%) \\
\text { with MetS }\end{array}$} & \multirow{2}{*}{$p$-Value ${ }^{1}$} & \multicolumn{6}{|c|}{ Number of MetS Components (Total $n /$ Percentage \%) } & \multirow{2}{*}{$p$-Value ${ }^{2}$} \\
\hline & & & & 0 & 1 & 2 & 3 & 4 & 5 & \\
\hline Overall & 93 & $\begin{array}{c}14 \\
(15.1 \%) \\
\end{array}$ & - & $\begin{array}{c}26 \\
(28.0 \%) \\
\end{array}$ & $\begin{array}{c}31 \\
(33.3 \%) \\
\end{array}$ & $\begin{array}{c}22 \\
(23.7 \%) \\
\end{array}$ & $\begin{array}{c}10 \\
(10.8 \%) \\
\end{array}$ & $\begin{array}{c}3 \\
(3.2 \%) \\
\end{array}$ & $\begin{array}{c}1 \\
(1.1 \%) \\
\end{array}$ & \\
\hline \multicolumn{11}{|l|}{ Sex } \\
\hline Females & 45 & $\begin{array}{c}9 \\
(18.8 \%) \\
5 \\
(11.1 \%)\end{array}$ & 0.3033 & $\begin{array}{c}12 \\
(25.0 \%) \\
14 \\
(31.1 \%)\end{array}$ & $\begin{array}{c}15 \\
(33.3 \%) \\
16 \\
(35.6 \%)\end{array}$ & $\begin{array}{c}12 \\
(25.0 \%) \\
10 \\
(22.2 \%)\end{array}$ & $\begin{array}{c}6 \\
(12.5 \%) \\
4 \\
(8.9 \%)\end{array}$ & $\begin{array}{c}3 \\
(6.3 \%) \\
0 \\
(0.0 \%)\end{array}$ & $\begin{array}{c}0 \\
(0.0 \%) \\
1 \\
(2.2 \%)\end{array}$ & 0.2770 \\
\hline $\begin{array}{l}\text { Region } \\
\text { Appalachian }\end{array}$ & 30 & $\begin{array}{c}11 \\
(17.7 \%) \\
3 \\
(10.0 \%)\end{array}$ & 0.3325 & $\begin{array}{c}18 \\
(29.0 \%) \\
8 \\
(26.7 \%)\end{array}$ & $\begin{array}{c}19 \\
(30.7 \%) \\
11 \\
(36.7 \%)\end{array}$ & $\begin{array}{c}14 \\
(22.6 \%) \\
8 \\
(26.7 \%)\end{array}$ & $\begin{array}{c}9 \\
(14.5 \%) \\
1 \\
(3.3 \%)\end{array}$ & $\begin{array}{c}1 \\
(1.6 \%) \\
2 \\
(6.7 \%)\end{array}$ & $\begin{array}{c}1 \\
(1.6 \%) \\
0 \\
(0.0 \%)\end{array}$ & 0.7795 \\
\hline
\end{tabular}

MetS: Metabolic Syndrome; ${ }^{1}$ Chi Square Test; ${ }^{2}$ Mantel-Haenszel test for trend.

\section{Discussion}

The prevalence of MetS students at West Virginia University (15.1\%) is much higher than what has been reported in previous studies $(0.6 \%$ to $10 \%)$ of MetS prevalence in college students $[1,7,16,17,22]$. Previous studies have reported the prevalence of MetS in young adults to be $0.6 \%$ [17] and $1.3 \%$ [16] in the Midwest region, 3.7\% [1] in the Northeast region and up to $10 \%$ in the Southeast region. Additionally, in the Northeast 7\% [1]; and in the Midwest 14\% [17] and 6\% [16] of students had two MetS risk factors, while $24 \%$ had two MetS risk factors in the Appalachian region. Showing that Appalachia has a markedly higher incidence of MetS $[1,7,16,17,22]$ and MetS risk factors $[1,16,17]$ than other regions of the US.

In a direct comparison of West Virginia University students to students from two Northeast universities (NEU1 and NEU2), the prevalence of MetS was significantly greater at WVU than both NEU1 ( $p$-value $<0.05)$ and NEU2 ( $p$-value < 0.05) [24]. The surprising lack of a significant difference between Appalachian and non-Appalachian student identity and the higher prevalence of MetS in WVU students suggests that an unidentified factor may be mediating the relationship with higher incidence of MetS in this population. One possible factor is BMI. Upon examining correlations between $\mathrm{BMI}$ and MetS components significant relationships were found. Specifically, BMI was significantly correlated with students presenting with at-risk WC $\left(R^{2}=0.86, p<0.05\right)$, low HDL $\left(R^{2}=-0.43\right.$, $p<0.05)$, elevated BP $\left(R^{2}=0.29, p<0.05\right)$ and increased TG $\left(R^{2}=0.22, p<0.05\right)$. No correlation was found between BMI and impaired FBG measures.

There are several limitations to this study. First, this was a small sample size of students. While this area of study is important, having a larger sample size would have increased the impact of these results. Overall, there was a generally low prevalence of MetS in this sample. Future work would include a larger sample size to have more impactful results.

These data identify the need for university administrators throughout the nation to implement health initiatives to measure BMI and screen for MetS components in students to prevent the development of chronic disease. Data from such screenings for college students will provide researchers, public health officials, and administrators with information to use to design, tailor, and implement effective interventions to prevent chronic disease progression across various university settings.

Author Contributions: Conceptualization, M.D.O., A.D. and R.A.W.; Data curation, A.D.; Formal analysis, A.D. and M.D.O.; Funding acquisition, M.D.O.; Investigation, M.D.O., A.D. and R.A.W.; Methodology, M.D.O. and A.D.; Writing—original draft, M.D.O. and A.D.; Writing—review \& editing, M.D.O. and R.A.W. 
Funding: This study was funded by the West Virginia University Hatch WVA00641.

Conflicts of Interest: The authors declare no conflict of interest.

\section{References}

1. Fernandes, J.; Lofgren, I.E. Prevalence of metabolic syndrome and individual criteria in college students. J. Am. Coll. Health 2011, 59, 313-321. [CrossRef] [PubMed]

2. Eckel, R.H.; Grundy, S.M.; Zimmet, P.Z. The metabolic syndrome. Lancet 2005, 365, 1415-1428. [CrossRef]

3. Grundy, S.M.; Brewer, H.B.; Cleeman, J.I.; Smith, S.C.; Lenfant, C. Definition of metabolic syndrome. Circulation 2004, 109, 433-438. [CrossRef] [PubMed]

4. Taylor, J.R.; Lopez, L.M. Cholesterol: Point-of-care testing. Ann. Pharmacother. 2004, 38, 1252-1257. [CrossRef] [PubMed]

5. Grundy, S.M.; Cleeman, J.I.; Daniels, S.R.; Donato, K.A.; Eckel, R.H.; Franklin, B.A.; Gordon, D.J.; Krauss, R.M.; Savage, P.J.; Smith, S.C., Jr. Diagnosis and management of the metabolic syndrome. Circulation 2005, 112, 2735-2752. [CrossRef] [PubMed]

6. Adult Treatment Panel III. Executive summary of the third report of the National Cholesterol Education Program (NCEP) expert panel on detection, evaluation, and treatment of high blood cholesterol in adults (Adult Treatment Panel III). JAMA 2001, 285, 2486-2497. [CrossRef]

7. Keown, T.L.; Smith, C.B.; Harris, M.S. Metabolic syndrome among college students. J. Nurse Pract. 2009, 5 , 754-759. [CrossRef]

8. Pancoska, P.; Buch, S.; Cecchetti, A.; Parmanto, B.; Vecchio, M.; Groark, S.; Paulsen, S.; Bardwell, G.; Morton, C.; Chester, A.; et al. Family networks of obesity and type 2 diabetes in rural Appalachia. CTS Clin. Transl. Sci. 2009, 2, 413-421. [CrossRef] [PubMed]

9. Blake, K.B.; Shankar, A.; Madhavan, S.; Ducatman, A. Associations among cardiometabolic risk factor clustering, weight status, and cardiovascular disease in an Appalachian population. J. Clin. Hypertens. 2010, 12, 964-972. [CrossRef] [PubMed]

10. Wu, T.; Snider, J.B.; Floyd, M.R.; Florence, J.E.; Stoots, J.M.; Makamey, M.I. Intention for healthy eating among southern Appalachian teens. Am. J. Health Behav. 2009, 33, 115-124. [CrossRef] [PubMed]

11. Griffith, B.N.; Lovett, G.D.; Pyle, D.N.; Miller, W.C. Self-rated health in rural Appalachia: Health perceptions are incongruent with health status and health behaviors. BMC Public Health. 2011, 11, 229. [CrossRef] [PubMed]

12. Ely, G.E.; Miller, K.; Dignan, M. The disconnect between perceptions of health and measures of health in a rural Appalachian sample: Implications for public health social workers. Soc. Work Health Care 2011, 50, 292-304. [CrossRef] [PubMed]

13. Williams, K.J.; Taylor, C.A.; Wolf, K.N.; Lawson, R.F.; Crespo, R. Cultural perceptions of healthy weight in rural Appalachian youth. Rural Remote Health 2008, 8, 932. [PubMed]

14. Smith, S.L.; Tessaro, I.A. Cultural perspectives on diabetes in an Appalachian population. Am. J. Health Behav. 2005, 29, 291-301. [CrossRef] [PubMed]

15. Barker, L.; Gerzoff, R.; Crespo, R.; Shrewsberry, M. Age at diagnosis of diabetes in Appalachia. Pop. Health Metr. 2011, 9, 54. [CrossRef] [PubMed]

16. Huang, T.T.K.; Shimel, A.; Lee, R.E.; Delancey, W.; Strother, M.L. Metabolic risks among college students: Prevalence and gender differences. Metab. Syndr. Relat. Disord. 2007, 5, 365-372. [CrossRef] [PubMed]

17. Huang, T.T.K.; Kempf, A.M.; Strother, M.L.; Li, C.; Lee, R.E.; Harris, K.J.; Kaur, H. Overweight and components of the metabolic syndrome in college students. Diabetes Care 2004, 27, 3000-3001. [CrossRef] [PubMed]

18. Racette, S.B.; Deusinger, S.S.; Strube, M.J.; Highstein, G.R.; Deusinger, R.H. Changes in weight and health behaviors from freshman through senior year of college. J. Nutr. Educ. Behav. 2008, 40, 39-42. [CrossRef] [PubMed]

19. Steinberger, J.; Daniels, S.R.; Eckel, R.H.; Hayman, L.; Lustig, R.H.; McCrindle, B.; Mietus-Snyder, M.L. Progress and challenges in metabolic syndrome in children and adolescents. Circulation 2009, 119, 628-647. [CrossRef] [PubMed]

20. Undén, A.-L.; Krakau, I.; Högbom, M.; Romanus-Egerborg, I. Psychosocial and behavioral factors associated with serum lipids in university students. Soc. Sci. Med. 1995, 41, 915-922. [CrossRef] 
21. Rozmus, C.L.; Evans, R.; Wysochansky, M.; Mixon, D. An analysis of health promotion and risk behaviors of freshman college students in a rural southern setting. J. Pediatr. Nurs. 2005, 20, 25-33. [CrossRef] [PubMed]

22. Morrell, J.S.; Lofgren, I.E.; Burke, J.D.; Reilly, R.A. Metabolic syndrome, obesity, and related risk factors among college men and women. J. Am. Coll. Health 2012, 60, 82-89. [CrossRef] [PubMed]

23. Dale, R.A.; Jensen, L.H.; Krantz, M.J. Comparison of two point-of-care lipid analyzers for use in global cardiovascular risk assessments. Ann. Pharmacother. 2008, 42, 633-639. [CrossRef] [PubMed]

24. Morrell, J.S.; Byrd-Bredbenner, C.; Quick, V.; Olfert, M.; Dent, A.; Carey, G.B. Metabolic syndrome: Comparison of prevalence in young adults at three land-grant universities. J. Am. Coll. Health 2014, 62, 1-9. [CrossRef] [PubMed]

(C) 2018 by the authors. Licensee MDPI, Basel, Switzerland. This article is an open access article distributed under the terms and conditions of the Creative Commons Attribution (CC BY) license (http:/ / creativecommons.org/licenses/by/4.0/). 